\title{
VIRTUAL PROFESSIONAL COMMUNITIES: INTEGRATIVE FACULTY SUPPORT TO FOSTER EFFECTIVE TEACHING
}

\author{
Katie Sprute, Grand Canyon University \\ Crystal McCabe, Grand Canyon University \\ Lynn Basko, Grand Canyon University \\ Paul Danuser, Grand Canyon University \\ Jean Mandernach, Grand Canyon University
}

\begin{abstract}
Growth in online and traditional course offerings has resulted in a subsequent increase in higher education's reliance on adjunct faculty. Supporting effective teaching for remote and traditional adjunct faculty presents several unique challenges (e.g., engagement, time, motivation, inclusion). To address these challenges, we wanted to establish a Community of Practice and launched course-specific Virtual Professional Communities (VPCs). VPCs were designed to provide a unique opportunity to connect faculty (full-time and adjunct) teaching the same courses to share instructional materials, dialogue about instructional challenges, and increase opportunities for networking. A reflective analysis overviews the challenges and benefits of utilizing VPCs with an emphasis on strategies to support teaching effectiveness in the online classroom.
\end{abstract}

Enrollment in traditional and online courses and degree programs continues to rise (NCES, 2019), resulting in the need for more faculty. Due to the high volume of students enrolled, more faculty are needed; however, because of budgetary restraints, institutions of higher education (IHEs) rely heavily on contingent, adjunct faculty (Barnes, 2017; Stenerson, Blanchard, Fassiotto, Hernandez, $\&$ Muth, 2010). Student success and retention rates are a consideration of IHEs (Anft, 2018). Therefore, the increased reliance on adjunct faculty mandates that institutions seek additional strategies that result in effective teaching, student retention, and are uniquely relevant to this faculty population.

Adjunct teaching has its benefits and downsides. While there is increased flexibility in selecting which teaching contracts to accept and the hours of availability, many adjunct faculty are working partor full-time elsewhere. The pay for adjunct faculty is less, yet many of the expectations are the same, and the preparation to teach a new course is extremely time-consuming. Some IHEs reported adjunct faculty turnover (Ramasamy, 2017). To minimize turnover and retain quality adjunct faculty, IHEs offer professional development (PD) opportunities (Magda, Poulin, \& Clinefelter, 2015). Unfortunately, adjunct faculty may not be able to participate in traditional PD offerings, such as Communities of Practice (CoPs) due to their circumstances with timing and location. "...professional development programs that are designed to meet the specific needs and circumstances of adjunct teaching faculty can enhance scholarly approaches to university teaching and learning practices. Specifically, strategically led, situated, and flexible communities of practice" (Webb, Wong, \& Hubball, 2013). The remote nature of the online adjunct faculty position warrants the need for various means of communicating what PD offerings are available and offer alternative modes of collaborating. 
Virtual Professional Communities (VPCs) are one way to cater to the unique geographical and timing barriers experienced by adjunct faculty. The following study provides an overview of the challenges IHEs and adjuncts face in providing and participating in professional development, as well as the benefits of utilizing a VPC for the development of adjunct faculty to support teaching effectiveness in the online classroom.

The purpose of this initiative was to explore a VPC model that can better support and foster effective adjunct teaching in both the online and traditional modalities. According to Mueller, Mandernach, and Sanderson (2013), adjunct faculty do not receive as high of ratings from students in the areas of learning, performance, and satisfaction. To address this, we created VPCs, which we called Faculty Circles (FC). Unlike other CoPs that highlight general topics such as assessment, grading, and lesson planning (Anft, 2018), our FCs were course-specific and allowed for participants to discuss a wide variety of topics and issues pertaining to each course. The researchers believed that course-specific FCs would be beneficial for faculty participants because it would allow for more support and assistance, making their job easier while enhancing the quality of their teaching. This initiative emphasized support for online adjunct faculty due to the frequency in which they teach course sections. The goals of this initiative are included in Table 1.

Table 1. Goals of Initiative

\begin{tabular}{|l|l|}
\hline \multicolumn{1}{|c|}{ Goals for Adjunct Faculty } & \multicolumn{1}{c|}{ Goals for the IHE } \\
\hline $\begin{array}{l}\text { Receive support prior to } \\
\text { taking over a course }\end{array}$ & $\begin{array}{l}\text { Utilize experienced faculty to } \\
\text { facilitate FCs }\end{array}$ \\
\hline Reduce workload & Highlight course-specific issues \\
\hline $\begin{array}{l}\text { Improve teaching } \\
\text { effectiveness }\end{array}$ & $\begin{array}{c}\text { Maintain or increase student } \\
\text { success rates }\end{array}$ \\
\hline Network with other faculty & $\begin{array}{l}\text { Provide opportunity for full-time and } \\
\text { adjunct faculty to collaborate }\end{array}$ \\
\hline
\end{tabular}

\section{LITERATURE REVIEW}

Goals for the FC initiative stemmed from the unique needs of adjunct faculty and the IHE. Institutional imperatives pertain to retention and cost effectiveness. The needs of adjunct faculty tend to be more focused on social and affective support, such as access to resources, the desire to have a voice, and the need to feel part of the university community.

\section{Institutional Needs-Retention}

Retention in higher education is imperative, not just for the success of the students, but also for the success of the institution. According to the National Center for Educational Statistics (2019), of the 1.5 million faculty in post-secondary institutions, $47 \%$ are part-time. In looking at what challenges adjunct faculty have experienced historically, they list the "... sense of feeling invisible, receipt of low pay, being underappreciated, lack of support, and assignment of courses with little notice prior to the first day of class" (Gappa \& Leslie, 1993, p.3). It is a clear connection with the same challenges that adjunct are experiencing today. These challenges impact the retention of adjunct faculty, and with the increase in demand for adjunct faculty to manage the enrollment of students, IHEs must pay attention to this.

\section{Institutional Needs-Cost}

Full-time faculty comprise about half of the workforce at many large IHEs. "Their short-term, inexpensive contracts, offering no obligation for renewal, provide institutions with much needed options in managing budgets" (Rowh, 2018, p. 41). There is quite a disparity in pay for full-time faculty versus adjunct faculty. The pay for adjunct is generally less than full-time faculty. The rates vary depending on institution type and the number of courses taught. Additional considerations in the cost comparison need to be made regarding the cost of providing benefits (Brennan \& Magness, 2018). IHEs are not likely going to hire more adjunct as full-time faculty because it would be exceedingly expensive and require significant reallocations budgetarily (Shulman et al., 2016). As IHEs continue to utilize adjunct faculty, they will need to consider other aspects of adjunct faculty's needs to retain them.

\section{Adjunct Needs-Community and Collegiality}

Two decades of online teaching have allowed many institutions to examine the effectiveness of the courses they are offering as well as the faculty members who teach and facilitate learning through this new environment. Tersoky and Heasley (2015) cited research stating a majority of faculty who teach in the online environment were dissatisfied 
with the support for professional development for the online faculty members. To offset the findings showing nearly $70 \%$ of online faculty surveyed who determined their IHEs were underperforming in the amount of support and incentives they provided for the online faculty (Terosky \& Heasley, 2015), it was determined two areas of improvement would be seen in the development of increasing community and collegiality through developing online courses and the teaching of those courses. Terosky and Heasley (2015) cited the nature of community as a group of people who have common interests or are engaged in common activities, such as the courses they teach or the very fact they are teaching in the same online environment for the same institution. Collegiality is devised from the framework showing four characteristics, "membership, influence, reinforcement of needs, and shared emotional connection" (Terosky \& Heasley, 2015, p. 149). When faculty members share similar experiences and know they have the support of leadership in their institutions, they are more willing to work together and are able to experience and share in their growth and development as educators in this setting.

\section{Adjunct Needs and Motivation}

Faculty are motivated for a variety of reasons to engage in CoPs. Many faculty members would like to acquire new resources for use within their courses and CoPs are one way to acquire these resources (Booth \& Kellogg, 2015). Additionally, some faculty members choose to participate in CoPs in order to have a voice at the institution they teach for (Glenn, 2016). These two needs are common motivators for faculty to participate in CoPs.

Resources. One aspect of online learning communities that drives faculty members to participate is the hope of acquiring new resources. Many institutions in the past several years have provided less professional development and expected faculty members to seek out their own learning opportunities (Evans, 2015). When faculty members are given professional development workshops, they are often limited to just a few new instructional ideas and there is very little chance for collaboration amongst participants (McKenna, Johnson, Yoder, Guerra, \& Pimmel, 2016). Research has shown that professional development is the key to higher student success rates (Carney,
Dolan, \& Seagle, 2015); therefore, faculty members are seeking out other opportunities for professional development. Online learning communities, also known as Online Professional Learning Communities (OPLC), or VPCs are one way faculty members can gain new professional insights through collaboration.

Online learning communities provide new resources and professional development to faculty members in a variety of ways. First, online learning communities allow faculty members to collaborate with one another, regardless of geographical location. Experienced faculty members have the opportunities to share their knowledge, while newer faculty members can share fresh ideas with veteran faculty (Booth \& Kellogg, 2015). By communicating stories and experiences, members of the online learning community can multiply their understanding of the content matter and pedagogy. Continued collaboration between members of the online learning community over time allows members to feel supported and increase their knowledge in their specific fields (Carney et al., 2015; McKenna et al., 2016). The camaraderie created within the online learning community creates a safe environment where new ideas and resources can be shared.

The second benefit of online learning communities, in regard to acquiring new resources, is the sharing of tangible ideas and resources, regardless of geographical location. Using an online model allows educators, who would otherwise not be able to collaborate, to share resources with one another. This is especially helpful to faculty members who are alone in their areas of study within their physical locations (Carney et al., 2015). Materials for teaching courses, creating discussion board materials, and even classroom management, can be shared virtually.

A final increase in resources that faculty members may experience by participating in an online learning community is technical resources. Research has shown that participation in these groups leads to increase in knowledge of how to use technology that many faculty members may not have been exposed to before (Booth \& Kellogg, 2015; Carney et al., 2015). Because these groups can take place in a variety of formats, including video conferencing, blogging, and social media, 
participants are often exposed to new technologies. This knowledge can then be used to enhance faculty members' engagement in their own classrooms.

Voice. Online faculty are just one of the voices that are needed to assist in contributing to professional development, changes and advancement of curriculum, and instruction of courses. Since many courses are taught by adjunct faculty, it would make sense to seek out their input; however, the adjuncts listed "feeling disrespected/ less valued than full-time faculty" as one of their primary challenges" (Cengage, 2017, p. 4). In addition to feeling disrespected and less-valued, in the research conducted by Cengage (2017), adjunct faculty also felt that they have limited influence on the courses they teach, which are often only offered courses that are available and not necessarily courses that they have requested.

Not providing opportunities for adjunct faculty to share their voice is not uncommon. As reported by Beaky, Besosa, Berry, Martinez, and Bradley (2013), the American Association of University Professors had recommended that adjunct faculty participate in campus and department decisionmaking. In research conducted by Ott and Dippold (2017), the participants reported not being included in decision-making and felt that their voices were missing from policies and goals of the college. By not seeking their input, it is also making adjuncts feel less respected for their ideas and expertise.

While there seems to be a lack of adjunct faculty voices, there is not a lack of desire to be involved. Development of courses, decisions on existing courses, perception on evaluations, contracts, and teaching techniques are all areas where adjunct faculty have shown a desire to participate more in (Ott \& Dippold, 2017). Even with a desire to participate, there are also challenges that adjunct faculty face in order to do so. With online education, adjunct faculty can be anywhere around the country, making it more difficult to schedule a time for them to gather and provide their input. Adjunct faculty typically work a full-time job outside of their adjunct responsibilities, which also can limit their available time to share their voices and opinions on matters. Professional development initiatives can be more effective when the voices of adjuncts are included (Anft, 2018). VPCs can be a way for adjunct to drive the development, and use their voice to express needs, wants, and ideas with other faculty given their disparate nature.

\section{Communities of Practice}

The online learning platform has become the norm in higher education. Golden (2016) stated nearly seven million students are now taking at least one online course through their colleges or universities. This ever-increasing number has caused IHEs to re-think and re-evaluate the way they plan for teaching their students and the acceptance of online education as the new normal way of meeting the needs of college and university students. Based on the increasing number of students taking online courses, it is also natural there would be more online faculty members as well. More IHEs are bracing for this and realizing support is needed for the faculty members who will be replacing their face-to-face instruction time with sitting in front of a monitor dealing with students they will never meet in person. Golden (2016) wrote of an extensive study in which communities of practice (CoPs) were established to provide help for online instructors.

CoPs are not created for attaining any deliverable on the part of the online instructors. Rather, they are created for the purpose of cultivating partnerships among the faculty members to help raise skills, awareness, and knowledge among the faculty members who are a part of the communities of instructors in the online community (Golden, 2016). Much like a Professional Learning Community in a traditional K-12 school environment, faculty members in CoPs interact and learn together to build a sense of trust and ownership with each other and with the materials they are presenting in the online learning community and format. When done correctly, even if the community is also conducted through the online platform, faculty members may build relationships with colleagues and leaders, which are supportive and allow for the opportunity of sharing best practices and reminding them they are not alone in the pursuit of teaching effectively, even though they are not in the traditional classroom environment (Golden, 2016). As more institutions offer online learning platforms, this is becoming more widely accepted in higher education, and the novelty of online instruction has worn off to the point of acceptance and continued improvement in the platform and levels of engagement between faculty members and students. 
While keeping with the existing model of CoPs, this research was focused on creating that collaborative partnership between full-time online faculty and adjunct faculty. The research at this institution differed from research at other institutions in the fact that adjunct faculty were specifically sought out in order to hear their voices, understand their needs, and help to motivate them, all while building that community. The modality that the discussions were provided were designed in a way that would allow adjunct to be active when it was convenient for them.

PD for teachers is not a new concept. Adapting PD practices in an ever-changing and dynamic learning environment in the 21 st century digital age requires a change in the paradigm of how PD has been delivered and functioning for the past several decades. Paskevicius and Bartolin (2016) maintained the need for contemporary PD opportunities to be ongoing and consistent, and the shorter, one-time only versions have little effectiveness in today's learning communities. The institution that serves as the home of this study is one of the fastest growing in the nation; therefore, the need for more faculty has also grown at alarming rates, often putting undue pressure on full-time ground and online faculty to mentor and train adjunct faculty who are coming to teach with a myriad of experiences and institutions' trainings, or lack of trainings, with them.

Old ways of training and developing need to be eliminated, and the new methods of training, developing, and even networking have to be part of the new way of onboarding adjunct faculty members. In doing so, they can be consistent with the practices of the institution and the topics, objectives, and assignments incorporated into the curricula, especially since the curricula is shared with hundreds, and sometimes even thousands, of students across the country.

Professional Development. From Parker's (2004) original assessment of who makes up the online faculty, it is natural to assume more faculty members teaching in online courses would not be current, traditional faculty members facilitating an online course from time-to-time to meet the initial needs of the institution offering these selections. Storandt, Dossin, and Lacher (2012) identified more current research that determined different skills were necessary to teach in the online format compared to those in a traditional face-to-face setting. The authors' (2012) study pointed out the desire of many online instructors was to have focused PD that would allow them to feel more confident and comfortable in teaching in the online platform. "Contingent faculty members who have taken advantage of development opportunities say they are more effective when adjuncts help devise them" (Anft, 2018, p. 8). Outcomes of PD for online faculty can be seen in providing skills in instructing students through the online platform, reducing turnover of online faculty, encouraging the students to complete the courses despite the connection of classmates in the traditional sense, and a sense of efficacy for the online instructors (Storandt et al., 2012). Given the increasing sense of the need for PD opportunities, it is logical to assume when improvements are seen on the parts of both the faculty and students, greater satisfaction can be seen, which would likely lead to greater productivity and retention of the online faculty members.

Our research provided the focused approach mentioned by Storandt et al., (2012) in that the PD was based on one course and facilitated by peers having experience in teaching the course. The topics addressed were grounded in course objectives, field-experience, and assessment. Those involved in this FC discussed assignments and ways to support students through effective contentspecific feedback.

\section{METHOD}

\section{Faculty Circles}

At this institution, our version of the VPC was referred to as Faculty Circles. The FCs were instituted for adjunct faculty who primarily were contracted to teach SPE-226 (Educating the Exceptional Learner) and ELM-210 (Instructional Planning and Assessments for Elementary Teacher Candidates). Because of consistently low student success rates and abnormally high failure and withdrawal rates, the majority of these course offerings were facilitated by full-time faculty, rather than adjunct faculty. The purpose of the FCs was to proactively engage in focused discussion with adjunct faculty about course objectives, specific assignments, and field experience requirements to avoid any reduction in success rates once the 
adjunct faculty took control of the classes. Fulltime faculty members who would act as peer mentors for the adjunct faculty introduced new methods of connecting the students and teachers through technology, such as Flipgrid, Loom, and Zoom, in an effort to increase student engagement, provide more effective and timely feedback, and to clarify assignment details.

Full-time faculty members had collaborated on the various resources for the classes with the desire to share these resources with the adjunct faculty, to provide consistency for all students in those classes, whether they were taught by the full-time faculty or adjunct faculty, ensuring the full experience of the faculty members. The FCs were also intended to provide more consistent and meaningful opportunities for the adjunct faculty to connect, collect, and share ideas for classroom instruction and engagement, as well as the opportunity to network with the seasoned, full-time faculty members in the online forum and ground campus. Whether it is because of distance or a lack of connection to the online teaching platform, many adjunct faculty feel neglected or displaced in the faculty continuum, and the FCs were instituted to ensure high quality instruction and assessment of student learning, as well as more of a connection with the College and the university.

\section{Participants}

The participants in this study were adjunct faculty who engaged in one of two peer-facilitated FCs which were asynchronous discussion threads focused on a specific course. The participants were invited to engage in the FCs based on their course approvals. Not all participants had taught the courses prior to the FCs. Of the 17 faculty who engaged in the two FCs, four agreed to be interviewed for this study. Two adjunct faculty resided in the city of the IHE; two faculty resided out of the state.

\section{Procedures}

The lead investigator gathered the names of faculty engaged in the FC from the FC site, then emailed a request individually to all faculty who engaged in the FCs to solicit volunteers to be interviewed. The requests were sent to the email associated with the IHE (i.e., university email address) and to secondary (i.e., personal) emails listed in the system when applicable. Faculty volunteering to be interviewed shared a preferred day and time for interview and then received a confirmation email with a link to a virtual meeting. Zoom, an online conferencing tool, was used to conduct the interviews. Interviews started with brief introductions of the investigators and participants. The lead investigator then requested permission to record the interviews, and questioning began. The interviews averaged 20 minutes. Targeted interview questions were asked in addition to a spontaneous line of questioning based on participant responses. Standard interview questions included:

1. What motivated you to register for this Faculty Circle?

2. What were you hoping to get from the experience?

3. How long did you participate?

4. Had you taught the class prior to the Faculty Circle?

5. Have you taught the class since?

6. Did you utilize any of the materials or resources from the discussion?

7. Why did you cease engagement? (if applicable)

8. What would be more helpful to you in the future?

\section{RESULTS}

Qualitative data gleaned from targeted interview questions and spontaneous lines of questioning was analyzed to identify content themes. Results of participant interviews revealed half of the participants interviewed had previously been involved in FCs. Themes emerged from interviews based on motivators for faculty participation in the faculty circles. The themes stemmed from the question pertaining to their motivation to participate in the FC (Table 2). Three predominant themes emerged; adjunct faculty participating in FC desire: 1) a voice in the classes they teach, 2) an opportunity to collaborate and engage with other faculty; and 3) new strategies and resources to use in their classes. 
Table 2. Interviewee responses to questions 3, 4, 5, 6

\begin{tabular}{|c|c|c|c|c|}
\hline & $\begin{array}{c}\text { Participant } \\
1 \\
\end{array}$ & $\begin{array}{c}\text { Participant } \\
2 \\
\end{array}$ & $\begin{array}{c}\text { Participant } \\
3 \\
\end{array}$ & $\begin{array}{c}\text { Participant } \\
4 \\
\end{array}$ \\
\hline Did you participate through the duration of the FC? & & $\mathrm{X}$ & & \\
\hline Had you taught the Class Prior to the FC? & & $\mathrm{X}$ & $\mathrm{X}$ & \\
\hline Have you taught the class since? & $x$ & & $\mathrm{X}$ & \\
\hline Did you utilize the course specific materials or resources form the FC? & $\mathrm{X}$ & & $\mathrm{X}$ & \\
\hline Did you utilize the web 2.0 resources since introduced in the FC? & & $\mathrm{X}$ & $X$ & $\mathrm{X}$ \\
\hline
\end{tabular}

\section{Motivations for Participation}

There were a variety of reasons for faculty registering to participate in the Faculty Circlesnamely the desire to connect with other faculty and to essentially confirm or ensure their teaching is commensurate with others. Other motivators included strategies to assist in carrying out duties in their full-time employment outside the university and role as mentor to other adjunct faculty within the university. These motivators are outlined in Table 3.

Table 3. Motivators for Faculty Involvement in Faculty Circle

\begin{tabular}{|c|c|}
\hline \multicolumn{2}{|c|}{ Motivations to Participate in the Faculty Circle } \\
\hline Participant1 & $\begin{array}{l}\text { - Connectedness } \\
\text { - See how others approach } \\
\text { assignments and tasks } \\
\text { - New strategies for self and for } \\
\text { meeting the needs of students } \\
\text { - Improve as facilitator }\end{array}$ \\
\hline Participant 2 & $\begin{array}{l}\text { - Involvement helps in her role as } \\
\text { an administrator } \\
\text { - New methods from other } \\
\text { instructors } \\
\text { - New ways to engage and } \\
\text { motivate students } \\
\text { - Getting ideas on the courses }\end{array}$ \\
\hline Participant 3 & $\begin{array}{l}\text { - Did not want to feel alone } \\
\text { - Wanted to be on same page as } \\
\text { other faculty } \\
\text { - Get ideas about what others } \\
\text { were doing }\end{array}$ \\
\hline Participant 4 & $\begin{array}{l}\text { - Talk to other professors } \\
\text { - Get to know other people } \\
\text { - Be able to share my insights to } \\
\text { help others } \\
\text { - Hear how other professors run } \\
\text { their classes }\end{array}$ \\
\hline
\end{tabular}

Voice

Knowing the importance of faculty voice, we wanted to actively seek input from adjunct faculty regarding their involvement in the FCs and illicit suggestions for future FCs. The participants were all very willing to share their thoughts and ideas about the FCs in which they participated. All participants expressed gratitude that the opportunity to participate in the FCs was available to them. Participant 4 shared her gratitude for the involvement in the conversation and stated, "It was really nice putting voices to email names." Given the line of questioning and responses from participants, a solid theme did not emerge regarding their interest in having more of a voice in terms of curriculum. What did emerge, however, was the lack of choice in the classes assigned. Participant 2 stated, "I'm teaching a different class again. It's almost like they give me a different class each time. I taught one class, I think, twice. A lot of times it is a new class." Upon further discussion, Participant 2 mentioned it would be preferred to be assigned the same course to teach more than once, so she can master it, then move on to a new course. Overall, faculty do not feel the need to contribute more to curriculum but prefer to have more of a voice in the classes assigned.

\section{Community and Collegiality}

While historically adjunct faculty have not felt supported and part of the university, the participants in these FCs all agreed that this was not their experience. Participant 3 shared, "There is a feeling of belonging in a group and getting support from the university and mentor teachers. You feel supported and it makes you happy and you feel like you belong." Participant 1 stated, "The FC made me feel like, as adjuncts, we feel like islands, but this made us feel like a community." Participant 4 stated, "I only teach 
online for [university], so it's also kind of a nice way to talk to some other professors. You know to kind of get to know some other people who are in this community, this virtual community." All participants indicated a motivation to participate from a desire to feel connected to their colleagues (Table 3).

\section{Professional Development}

The FC did not have a specific time frame that it would be running, and participation was not mandatory. While there is no requirement for adjunct faculty to attend PD, Participant 4 stated, "You might want to require PD for the year. We never change if we do not go to these opportunities." Participant 1 shared, "I love the collaboration and frequency of the online trainings; they are beneficial." Participant 1 also expressed the desire to see how others approach similar tasks, get validation and new ideas. Participant 4 stated these professional developments allow her to "...hear how other professors run their classes." Participant 2 suggested weekly Discussion Questions (DQs) to keep the conversation and collaboration going. Participant 1 requested a greater frequency for these PDs. Participant 1 also requested PDs be offered each time there is a curriculum change. Adjunct instructors prefer a focused PD to increase confidence and comfort in teaching.

\section{Resources}

Through the duration of both FCs, resources and Web 2.0 tools were shared by the facilitators. When asked, participants specifically highlighted the Web 2.0 tools. Participant 3 mentioned templates and how the Remind app could be used to support students. Participant 2 stated, "I got Flipgrid from this! I'm always looking for strategies to engage the kids." Participant 4 shared, "The videos are very helpful." The course specific materials, such as announcements and posts had been utilized by those who had the opportunity to teach the class again since the FC concluded.

\section{Participants' overall perceptions and suggestions}

While each participant was excited about participating, most participants shared they wished the FC had taken place during a time when they had been teaching the courses. Participant 2 shared, "Engagement might have been higher if currently teaching the course or if it was recently taught or coming up." Participant 3 stated, “... would love to participate again in the future. Might even work better if it happened during the course." Additionally, Participant 4 believed that offering an incentive for attending would be a good idea. Essentially, participants felt the FCs were a positive experience, but they would be more relevant if they were teaching the class discussed at the same time.

\section{DISCUSSION}

The FCs provided some faculty the opportunity to share their voices in their interview responses for the FC. All participants had previously been involved in mentorship programs with the University, either as mentors or mentees, which provided an opportunity to share knowledge among other faculty. This allowed participants a voice and a sense of community with instructors familiar with the same content.

The Web 2.0 tools shared in the FCs were greatly appreciated and have been used in subsequent classes. While the content-specific resources were of value, they were underutilized because faculty had not been subsequently assigned the classes to teach that were discussed in the FCs. This is an indicator that faculty would benefit from the opportunity to teach a class more than once. Overall, the opportunity to collaborate with other colleagues and resources shared were beneficial to the participants.

\section{FUTURE IMPLICATIONS}

Historically, IHEs have seemed to underutilize their adjunct faculty as experts and potential contributors to professional development. Professional developments were offered to full-time faculty, but adjunct faculty were overlooked for these opportunities. This study utilized technology to reach the adjunct faculty of two classes to help provide them with a VPC. While this study found there to be many positive outcomes from the VPC, there are some recommendations:

- Utilize data in selecting courses for VPCs such as Student Success Rates (SSRs), continuous enrollment, as well as End-OfCourse Surveys (EOCS).

- Send an invitation only to faculty who have previously taught the class. 
- Hold the VPC at a time when the faculty member is about to teach the course or is currently teaching the course. This allows for immediate implementation.

- At the start of the VPC, ask participants what they want and need from the discussion regarding the class (resources, feedback on the course, collaborate with other faculty).

- Identify weekly goals and objectives to discuss based on feedback from the faculty and course data.

- Course-specific VPCs should have a predetermined start and end date to allow for consistent commitment and time management for all participants and facilitators.

- Select a full-time faculty member or staff member to serve as a point of contact regarding the course of focus in the VPC.

- At the end of the VPC, survey participants to illicit feedback regarding their experiences and suggestions for subsequent offerings.

- Work with faculty schedulers to ensure participants are assigned the specific course of the focus of the VPC in the near future.

- Facilitators of the VPC and college leadership should review sections taught by the participants to analyze performance and student achievement (SSRs and continuous enrollment as well as EOCS).

\section{LIMITATIONS AND FUTURE RESEARCH}

One limitation to this research is the number of faculty interviewed. Only four adjunct faculty were willing to be interviewed for the purposes of this study. A larger sample size would be beneficial in examining faculty involvement in VPCs.

Given the feedback from participants, engagement waned for one primary reason. Participants stated they would have likely been more involved if they were teaching the course at the same time as the FC was taking place. Future research should include FCs running simultaneously to the faculty teaching the class.

\section{CONCLUSION}

This study provided an overview of the challenges IHEs and adjuncts face in providing and participating in professional development, as well as the benefits of utilizing a VPC for the development of adjunct faculty to support teaching effectiveness in the online classroom. Despite the historical differences in pay and other challenges, the participants in this study did not indicate money as an issue, instead, adjunct faculty have indicated a desire to participate in professional development and to be part of a community. One method of providing professional development and a sense of community to faculty residing all around the world is by COPs such as VPCs. Based on this idea, the faculty at this IHE created course-specific FCs to establish community and provide a venue for professional development through share ideas, experience, resources, and best practices. Participants from the FCs were interviewed regarding their experiences. Results indicated it was a positive due to the resources and ideas gleaned from other faculty approved to teach the same classes. There is opportunity for improvement, however, such as teaching the classes at the time of the FC. More work is needed, and the team is excited to continue the research to foster positive participation from both the full-time and adjunct faculty members at this, and potentially, other IHEs as well. 


\section{REFERENCES}

Anft, M. (2018) Colleges step up professional development for adjuncts. Chronicle of Higher Education, 65(16), 8.

Barnes, C. B. (2017). Size, characteristics, compensation, and work experiences of adjunct and other non-tenure-track faculty. GAO Reports, p. i-106. Retrieved from https://www.gao.gov/ assets/690/687871.pdf

Beaky, L. A., Besosa, M., Berry, J., Martínez, P., \& Bradley, G. (2013). The inclusion in governance of faculty members holding contingent appointments. Academe, 99(4), 77-89.

Booth, S., \& Kellogg, S. (2015). Value creation in online communities for educators. British Journal of Educational Technology, 46(4), 684-698.

Brennan, J., \& Magness, P. (2018). Are adjunct faculty exploited: Some grounds for skepticism. Journal of Business Ethics, 152(1), 53-71. doi-org.lopes.idm.oclc.org/10.1007/s10551-016$3322-4$

Carney, M., Dolan, D., \& Seagle, D. (2015). Intentional collaborations: Building a virtual community of mentoring and practice. Association of American Colleges and Universities, 17(4), 8-10.

Cengage. (2017). Experiences, challenges, and perspectives of adjunct instructors [White paper]. 1-8. Boston: Cengage.

Retrieved from https://assets.cengage.com/pdf/wp_ experiences-of-adjunct-instructors.pdf

Evans, P. (2015). Open online spaces of professional learning: Context, personalization and facilitation. TechTrends: Linking Research \& Practice to Improve Learning, 59(1), 31-36.

Gappa, J., \& Leslie, D. (1993). The invisible faculty. San Francisco, CA: Jossey-Bass.

Glenn, G. (2016). Colleges increasingly replacing full-time faculty with adjuncts. Retrieved from https://www.wfae. org/post/colleges-increasingly-replacing-full-time-facultyadjuncts\#stream/0

Golden, J. E. (2016). Supporting online faculty through communities of practice: Finding the faculty voice. Innovations in Education and Teaching International, 53(1), 84-93. doi:10.1080/14703297.2014.910129

Magda, A. J., Poulin, R., \& Clinefelter, D. L. (2015). Recruiting, orienting, \& supporting online adjunct faculty: A survey of practices. Louisville, KY: The Learning House.

McKenna, A., Johnson, A., Yoder, B., Guerra, R., \& Pimmel, R. (2016). Evaluating virtual communities of practice for faculty development. Journal of Faculty Development, 30(1), 31-39.
National Center for Education Statistics. (2019). Characteristics of postsecondary faculty. Retrieved from https://nces.ed.gov/ programs/coe/indicator_csc.asp

Ott, M., \& Dippold, L. (2017). Part-time faculty involvement in decision-making. Community College Journal of Research and Practice, 42(6), 452-455.

Parker, A. (2004). Identifying incentives for faculty who teach at a distance: An analysis of the literature. College \& University Media Review, 10(1), 9-15.

Ramasamy, V. (2017). Faculty's turnover in private higher learning institutions: A phenomenal inquiry. Business \& Economic Horizons, 13(2), 169-181.

Rowh, M. (2018). Paying up: Institutions increase adjunct faculty pay while making them feel valued on campus. University Business, 3, 41-43.

Shulman, S., Hopkins, B., Kelchen, R., Mastracci, S., Yaya, M., Barnshaw, J., \& Dunietz, S. (2016). Higher education at a crossroads: The economic value of tenure and the security of the profession. Academe, 102(2), 9-31.

Stenerson, J., Blanchard, L., Fassiotto, M., Hernandez, M., \& Muth, A. (2010). The role of adjuncts in the professoriate. Peer Review, 3, 23-26.

Storandt, B. C., Dossin, L. C., \& Lacher, A. P. (2012). Toward an understanding of what works in professional development for online instructors: The case of PBS Teacherline. Journal of Asynchronous Learning Networks, 16(2), 121-162.

Terosky, A. L., \& Heasley, C. (2015). Supporting online faculty through a sense of community and collegiality. Online Learning, 19(3), 147-161.

Webb, A. S., Wong, T. J., \& Hubball, H. T. (2013). Professional development for adjunct teaching faculty in a researchintensive university: Engagement in scholarly approaches to teaching and learning. International Journal of Teaching and Learning in Higher Education, 25(2), 231-238. 